\title{
What industry wants: Employers’ preferences for training
}

Purpose -This paper describes and analyses what retail and hospitality industry employers want from training and trainers.

Methodology - The research project was undertaken for Service Skills Australia, the Australian Industry Skills Council that oversees formal training for a range of service industries in Australia. The paper utilises data from focus groups and telephone interviews with representatives of the retail and hospitality industries, and telephone interviews with staff of the relevant UK Sector Skills Councils, to provide international benchmarking for the issues raised.

Findings - Results showed that while industry representatives stated they prioritised industry skills and knowledge above education skills and knowledge, a complex mixture of the two was required, which was generally felt to be lacking. Curriculum for training was also perceived to be deficient, despite Training Packages having been developed in consultation with industry. A comparison with the UK interviews with senior staff at the UK skills councils for the two industries, showed similar issues and suggested some possible ways forward for Australia.

Keywords Human resource development, Learning and development, Apprenticeships and traineeships, National human resource management policies, Retail, Hospitality.

Paper type Research paper

Service industries predominate in western economies and yet there remains a perception that they and the jobs that they create are somehow inferior to jobs that produce goods rather than services. Training for most jobs in the service industries suffers from a similar perception, with qualifications in the most part fairly recently established, and formal provision of qualifications more likely to be provided by the private training sector rather than public providers. Perceptions of poor quality training are accepted as not entirely unfounded, and hence a series of three research projects, collectively known as the 'New Deal', was commissioned in 2008-9 by Service Skills Australia, the Industry Skills Council for the service industries, with the aim of gathering research evidence to inform the development of initiatives to improve the quality of service skills training. This paper reports on part of the research undertaken for the second of the three projects. This project was intended to provide suggestions for better developing vocational education and training (VET) practitioners for the service industries, in the belief that better development for these teachers and trainers was one factor that would lead to higher quality training. The aim of this paper is to report on and critique what industry representatives said about training and trainers for the industry, and to derive suggestions for improvements.

The coverage of the Skills Council extends to a substantial number of service industries, but this paper confines itself to findings related to retail and hospitality, which are the two largest service industries as in Australia, as in many economies. The paper draws upon data from focus groups with representatives of these two industries as well as upon interviews with senior staff at the UK skills councils for these two industries. The latter interviews were designed to inform the outcomes of the Australian project. The project as a whole (Smith, Brennan Kemmis, Grace and Payne, 2009) also incorporated a survey of all Registered Training Organisations (RTOs), public and private, delivering training for the service industries $(n=1760)$ and case studies in eight RTOs. The study focused primarily upon 
formal training as expressed through VET qualifications, but did not exclude non-accredited training.

\section{Background and literature review}

In Australia, the service industries are by far the biggest employers of labour. In 2008, retail, including floristry and wholesale, employed 1.5 million people (Service Skills Australia, 2009a) and hospitality, including tourism and travel, 1.2 million (Service Skills Australia, 2009b). The retail and hospitality industries are expanding rapidly in western countries. In the UK, for example, restaurant trade increased by 71\% in the decade to 1998 (Pratten, 2003). Internationally around $10 \%$ of all workers are employed in tourism and hospitality alone (Baum, 2002).

Despite their massive size, work in these two industries is often undervalued by the public and by scholars alike (Poulston, 2008; Hart, Stachow, Farrell and Reed, 2007). Perceptions of low skills are, of course, often socially constructed (Baum, 2002). However, the work certainly has its real disadvantages; for example hospitality workers are sometimes subject to split shifts and cramped working conditions (Pratten, 2003). Pay also tends to be low (Pratten, 2003), although jobs are very diverse and include managerial and professional work (Baum, 2002). In the tight labour market of the past decade it has been increasingly difficult to attract staff to many jobs in the industries (Poulston, 2008). Labour turnover is high (Booth and Hamer, 2007) partly because the workforce tends to be young and, especially in hospitality, transient. In the UK, and Ireland in particular, for example, hospitality has attracted huge numbers of workers from the EU 'A8 accession countries' such as Poland (Wickham, Moriarty, Bobek and Salamonska, 2009) which brings additional training needs such as language training as well as a workforce that does not intend to stay in the industry. Students both in secondary (Smith and Wilson, 2002; Smith and Patton, 2007) and tertiary education (Greenbank, Hepworth \& Mercer, 2009) form a large proportion of the industries' workforces.

Apart from training for chefs and other food-related trades such as butchers and bakers, qualifications are not yet a prerequisite for employment in either industry (Huddlestone and Hirst, 2004), and managers in particular are under-qualified (Hart et al., 2007). The retail and hospitality industries are 'low consumers' of external training, particularly that offered by public training providers (Dougherty, 2003). This could partly be related to the typical size of retail and hospitality employers, which tend to be small (Service Skills Australia, 2009a and 2009b); on-the-job training is generally agreed to be the most common type of training in small and medium enterprises (eg Jameson, 2000). Employers sometimes tend to express dissatisfaction with training provided by external providers (Pratten, 2003). There are some difficulties with on-the-job training, however, in the service industries; as Poulston (2008) puts it, 'performing a task publicly with insufficient skill jeopardises service quality, and can demean and embarrass employees'.

Customer service is paramount in these industries; Maxwell, Watson and Quail (2004, p. 159) point out that for hospitality 'the customer reigns supreme', and Huddlestone and Hirst (2004, p. 6), for retail, state 'customer service is becoming the most essential employee skill.' In a study of training in the Hilton chain, Maxwell et al. (2004, p. 269) note that a service culture is deeply imbued in organisational structures and practices, and cannot be added on simply by training individual staff. 
Training for the service industries in Australia is carried out predominantly within the framework of the national Vocational Education and Training (VET) system. National qualifications are built into industry Training Packages which contain job-related units of competency developed in consultation with industry and training providers. Qualifications are delivered by Registered Training Organisations (RTOs) which consist of both public providers, mainly TAFE (Technical and Further Education) Institutes, and around 4000 private providers (Smith and Keating, 2003). Apprenticeships and their newer siblings, traineeships, account for about $25 \%$ of VET activity and consist of a combination of employment and training, sometimes involving part-time attendance at an RTO but in the case of traineeships often involving on-site training only and visits from an RTO trainer (Smith, Comyn, Brennan and Smith, 2009). In hospitality, chefs, and, in retail, butchers and bakers are generally apprenticed jobs. Traineeships are common in retail and in fast food establishments, although their use is increasingly becoming strategic rather than mass (Smith, Comyn, Brennan and Smith, 2009).

Challenges associated with researching the topic area included the diverse nature of the VET workforce in general (Smith and Keating, 2003), the highly distributed nature of the segment of that workforce providing training for and within service industries, the relatively recent provenance of nationally recognised training (qualification-based) in some of the service industries, the fragmented nature of several of the service industries themselves (e.g. the fitness and beauty industries), and the known quality issues and issues of competition among training providers particularly in the private training sector, which, it was expected, would lead to some reluctance to participate in the research study.

\section{Research method}

Four focus groups (two in retail including floristry and wholesale, and two in hospitality including travel and tourism) were held in three States in Australia during May 2009, with senior industry representatives, who were accessed primarily through Service Skills Australia recommendation. In hospitality, two people unable to attend were contacted separately through telephone interviews. Participants were predominantly employers, although in some cases they were from employer associations. The employers continued two Group Training Organisations (GTOs), which are government-supported companies that employ apprentices and trainees, 'leasing' them to employers. In the case of hospitality, there were several representatives from training providers rather than employers, which is a limitation of the data, although at least one of these had only very recently ceased to work in the industry. Tables 1 and 2 detail the participants.

\section{“Take in Table (No. 1)"}

\section{“Take in Table (No. 2)”}

Focus groups lasted for 1.5-2 hours and interviews for 30-45 minutes. Questioning areas included the nature of the industry, the nature of the workforce in the industry, the major features of training in the industry, the nature of trainers who deliver training in and for the industry, the expectations that participants had of trainers delivering training for their industry, gaps between expectations and the reality, and any differences between those delivering at training providers and those working within enterprises. Participants were also asked to locate, on a five-point scale that opposed industry skills and knowledge with 
education skills and knowledge, the position where they believed that teachers and trainers for their industries should occupy.

Also, telephone interviews were undertaken with the research officers from People1st and Skillsmart, the UK skills councils for hospitality and retail respectively. These interviews, lasting between 30-45 minutes, were designed to benchmark with another country's system the differences or similarities in the issues the industries were facing with regard to training needs and training provision, and to find out whether the relevant UK players had introduced any strategies to address challenges. Desk research was also carried out on the two skills councils' web sites and in relation to VET teaching and teachers more generally in the UK.

While the sample of industry representatives accessed was small and was directed by the Skills Council, the findings reported were congruent with the literature as discussed earlier and with other research carried out by the research team (eg Smith, Comyn, Brennan Kemmis and Smith, 2009). Internally, the data indicated strong similarities between the Australian and UK situations. Hence it is felt that the data are reliable.

\section{Findings}

This section reports on the data gathered during the focus groups and interviews.

The nature of the industries

While both industries predominantly consisted of small and medium businesses there were a number of major players, which included some operating mainly on a franchise model. Some major companies operated in both sectors; for example the two largest supermarket chains also owned large numbers of pubs. The industries generally experienced low volatility, but some sub-sectors such as florists and liquor stores experienced high business turnover. Many businesses had extended opening hours, some in retail as well as hospitality operating 24 hours a day seven days a week. The Global Financial Crisis had affected hospitality differentially across States, and had not had much impact on retail at the time of the research.

The nature of the workforce in the industries

Because of their extended opening hours and fluctuations in trade over a working week and year, both industries relied heavily on part-time workers and particularly student labour, although some sub-sectors such as hardware preferred to use full-time mature staff. Respondents reported significant labour shortages in sub-sections of the industries, for example chefs, travel agents, and managers in both retail and hospitality. The GFC had, however, removed the extreme tightness of the labour market - when 'if you've got a heartbeat you're employed' (hospitality employer) - and was also creating some movement among the industries. For example, retail was receiving some workers displaced from hospitality front-of-house positions.

The nature of training for the industries

In hospitality, the apprentice model was still used heavily for chefs. Chef training could also be undertaken entirely within an RTO (with work placements) and this model was common 
for overseas students studying in Australia. There were also large numbers of students undertaking VET in schools programs in hospitality, and many employers spent large amounts of time managing these students' work placements. In the retail industry, traineeships were more common than in hospitality and larger companies had extensive inhouse training programs (as did some hospitality employers, albeit this was less common in hospitality) that might or might not receive national recognition. Some enterprises were enterprises RTOs (Smith and Smith, 2009), which offer qualifications to their own workers. In both industries it was stated that most smaller and medium-sized employers did not focus so much on training as might be liked, although fine-dining restaurants, for example, would hold daily training sessions.

The nature of the training workforce for the industries

Participants felt that TAFE trainers tended to be on average of 'baby boomer' age and had sometimes lost touch with their original industry areas, while those in private RTOs tended to be younger but there was high staff turnover in private RTOs. It was also sometimes, although by no means always, the case that staff in private RTOs taught across a range of industry areas and were said to be expert in none. Within enterprises, training was often undertaken by managers who also had other roles. This was particularly common in the restaurant business.

Expectations of trainers and the way in which the industry sees trainers

Both industry groups felt that the most important skills and knowledge for trainers to possess were related to industry rather than education (see Tables 3 and 4, which report the responses of participants to the 'industry-education scale'). Hospitality responses were more polarised than retail.

“Take in Table (No. 3)”

\section{“Take in Table (No. 4)”}

Data from the focus group participants was used to develop the following list of ideal attributes for trainers:

\section{Industry related}

- Close engagement with the relevant industry.

- The ability to talk to students about the working environment and what employer expectations will be. (This is especially important for overseas students).

- The ability to outline career paths.

- A need to be experienced in the industry in operational areas and also have held a management position. The reason for the latter is that 'they need to have a grasp of the big picture and be able to impart that' - they need to tell workers why things need 
to be done the way they are done - for example in terms of risk management or budgetary reasons.

- Up to date skills - especially in technical skills when technology moves on. For example, one hospitality participant said 'If you trained in beer service using direct pull, you are out of date; they don’t do direct pull in serving beer any more.'

- The ability to relate what they are imparting to the reality of individual workplaces; and to show students how to do the same - but, as one participant said, 'it's difficult to build it into their students' minds.'

- The ability to convey to students the importance of a customer service orientation.

\section{$\underline{\text { Pedagogy related }}$}

- The ability to keep and demand discipline; in the hospitality industry this was felt to be particularly important because kitchen staff are expected to be very obedient.

- Conveying a sense of fun.

- Understanding training and learners - 'how to tap into the abilities of your learners' how to make learning interesting.

- An ability to recognise that different contexts and locations demand different pedagogies and content focus.

- A capacity to administer RPL (Recognition of Prior Learning) processes skilfully.

- High level assessment skills.

This list is a demanding one, and it is perhaps not surprising therefore that there was a reasonable amount of dissatisfaction with the training workforce. In many cases this dissatisfaction was tied up with a perception of low quality in the training qualification (Certificate IV in Training and Assessment) that is now the minimum (and often maximum) qualification for delivering formal VET. This perception of the qualification is well supported in the Australian VET literature more generally (e.g. Simons and Smith, 2008). One participant, however, from a major employer association, felt very strongly that it was inappropriate for enterprise trainers to need formal training qualifications at all, saying that the requirement for this had caused some employers to 'walk away from the VET system'.

Beyond a general disquiet, participants expressed dissatisfaction with the industry knowledge and currency of trainers. However, some examples were provided of individual trainers or RTOs where industry currency was felt to be very high, and where trainers made great effort to maintain contact with employers and with the industry more generally. It was said that TAFE in New South Wales had formerly run 'return to industry' programs for teachers, but no longer did so.

Some disquiet was also expressed about the standard of training delivered, particularly with regard to the imparting of service standards to learners. To some extent this was felt to be related to deficiencies in the curriculum (Training Packages) for the industries and not entirely attributable to the teachers. Employers of chefs felt that the technical skills delivered by different providers was not consistent; for example it was agreed among participants in one group that there was no guarantee that a second year apprentice, for example, was at a similar standard across providers, nor across employers. It was also suggested that a chef trained entirely in an RTO, even with periods of work placement, had skills of a completely 
different standard (ie lower) from one trained through the apprentice system. More generally, some concern was expressed that assessment practices were not rigorous enough and that therefore it was not always possible to trust the skill levels of VET graduates.

It was noteworthy, particularly among the hospitality employers, that while many criticisms of trainers and training providers were voiced, employers also made many 'excuses' for them, emphasising how difficult it was to keep abreast of industry practice and also how difficult it was for training providers to navigate the complex world of VET.

\section{Findings from the UK interviews}

As in Australia, these two industry sectors were very large. Hospitality, tourism and travel employed about 2 million people, from a total UK workforce of about 28 million, (People1st, 2009), in 180,000 establishments. Retail employed 3 million people (one in nine of the workforce) across 291,000 businesses. Both interviewees stated that their industries were highly polarised between large multi-site employers and micro-businesses. Both industries employed large proportions of part-time workers including students and, particularly in hospitality, itinerant and migrant workers; and both had a tradition of high labour turnover. Hospitality, travel and tourism had been hit badly by the recession of 2008-9, particularly in the pub sector. The recession, as in Australia, had provided opportunities for crossfertilisation among industries as people lost their jobs in one sector and looked to move into other work where the skill set was similar (People1st, 2009). The standard of service in both industries was felt to be lower than required (especially in a situation where customer expectations were continually rising), with both industries also reporting a need for improved management skills. The hospitality industry had a skill shortage in chefs (People1st, 2009).

In these two industries most training was informal. A very small proportion of training was carried out in further education (FE) colleges (5\% in retail and $14 \%$ in hospitality, tourism and travel).The private sector and employer training accounted for the rest. In hospitality, chef training had traditionally been carried out at FE colleges, but the National Vocational Qualification ${ }^{1}$ curriculum, predicated on workplace delivery, was found to be unworkable and the industry had therefore introduced a new college-based Diploma in Professional Cookery at FE colleges as well as planning other Diplomas in hospitality and travel (People1st, 2009). Both interviewees stated that major employers had highly professional training departments and that training within these companies is often focused on 'brand standards'. Both stated that off-the-job training delivery was often not suited to industries where customer interactions drove skills development.

Retail had many large private training providers, which tended to have contracts with major employers nationally. As much of the accredited training was 'work-based' (i.e. 100\% on-the-job) there was an emphasis on assessment rather than on training. An example was given of a chain of pubs, which are working with a qualification awarding body in an arrangement where the pub managers are accepted by that body as able to undertake the assessment for an apprenticeship for bar staff. Both industries had taken up the UK national initiative of Skills Academies, designed to showcase best practice - to show the sectors what was the expectation of a high quality training provider. Retail had adopted a highly distributed model with 70 of these planned around the UK, while hospitality was focusing on less than 10 . Both Skills Councils had developed their own training courses in two areas felt to be deficient - service skills and managerial skills - which were delivered through the Skills Academies. In

\footnotetext{
${ }^{1}$ NVQs are similar to Australian Training Packages.
} 
the case of retail, a service skills course for shop floor staff had a parallel management course so that managers were conversant with the requirements for shop floor staff.

Industry currency was raised as an issue, as in the Australian focus groups. There was a 'lecturers into industry' scheme in hospitality, although not, it seemed, in retail. A hospitality example was given from Northern Ireland. A lecturer had spent two weeks in a famous chef's kitchen in a structured program with special emphasis on patisserie skills. He introduced these back into his college-and arranged a deal for placements for four students at the kitchen as well. In another example, two lecturers had undertaken placements in the restaurant of Gordon Ramsey, a famous television chef.

More generally in relation to VET teaching qualifications, the UK had introduced a new system to allow for a lower-level 'passport' within the QLTS ('Qualified Teacher Learning and Skills' licence), for people delivering training only in their specialist area. The retail interviewee mentioned the use of contractual leverage rather than regulation to enforce teacher qualifications- in other words training providers (other than FE colleges, where the qualification was mandatory) did not receive government funding unless their teachers were qualified. This interviewee also mentioned a Bespoke Accreditation Scheme where employers could seek 'blanket' coverage of their training staff so that their trainers need not all be licensed.

\section{Discussion and conclusion}

Industry participants and the UK informants painted a picture of complex industries where many businesses were small and medium enterprises, and therefore incurred all the normal disadvantages of smaller business with regard to training. In addition to this, long opening hours and peaks and troughs in trade meant that the workforce was inherently fragmented and unstable, relying heavily on casual staff. Moreover, the industries were expanding rapidly. There was a lack of tradition of training in the industries compared with other industries, with relatively new qualifications for most jobs, and managers in the industries were underqualified, meaning it was difficult for them to drive high standards in training. Given these circumstances it is perhaps surprising not that training for the service industries exhibits many challenges, but that it does the job as well as it does. This observation was supported by hospitality employers who acknowledged the difficulties faced particularly by TAFE teachers, and were very ready to make excuses on their behalf.

There seemed to be three major areas where improvement in VET training and trainers would be welcomed. These were industry engagement, pedagogical (including assessment and RPL) skills, and more generally the need for teachers and trainers to impart the 'service ethics' to their students. The latter was an attitude rather than a technical skill. The following initiatives from the UK could be useful framing improvements in these three areas:

- Structured return to industry schemes with a definite curriculum for the learning of the 'returning' teachers, which addresses the industry-related attributes of an ideal teacher or trainer outlined above.

- The acknowledgement of the likely continued predominance for workplace delivery in some service skills areas, and hence the need to find non-traditional ways of building teacher expertise in the recognition that there will never be large bodies of teachers who deliver on-site at RTOs.

- Realignment of national VET teacher/trainer qualifications and requirements to allow for a lower-level training 'passport' for people training only in their specialist area 
and a higher-level qualification (ie above the current Certificate IV in Training and Assessment) for those who have a full-time teaching or training role. The latter qualification should include the pedagogy-related 'ideal attributes' outlined above.

- Greater benchmarking among training providers in relation to assessment standards.

- Involvement of Skills Councils in developing courses to address deficiencies in customer service skills that are not addressed by relevant national qualifications and to ensure the appropriate delivery of such courses and their embedding in workplace practice (i.e. supporting courses for training providers and for managers).

Beyond the areas for improvement that are listed above there seems to be an underlying problematic issue. Employers in both countries seem to suggest that deeper levels of service skills are required and that current VET training and trainers do not sufficiently develop these skills in learners. And yet in both countries employers and employer associations are heavily involved in the development of Training Packages and NVQs respectively, and so it might be expected that qualifications would reflect industry requirements. There are several explanations for this seeming disparity. It could be that actually employers need their workers to have technical skills, but they would also like them to have better attitudes, and that in their comments they focus on deficiencies rather than strengths. Or it could be that employers are unable to communicate what they mean by service skills to those developing these qualification regimes, or that those people ignore what employers are telling them. It is also possible that teachers lack the skills to develop service skills in learners. More fundamentally it may the case that such skills cannot be taught in isolation from an organisational culture, because, as Maxwell et al. (2004) point out, a service culture is so deeply embedded within organisational culture. It is also possible that some learners cannot learn them, or are not interested in learning them. In the study of Polish hospitality workers in Ireland (Wickham et al., 2009, p. 92), a worker referred to two groups of workers - those who 'think business' and those who 'simply want to do their job and go home'. Given this dichotomy it may be that it is unrealistic to expect that the VET system can develop deep service skills in the full range of workers. However greater engagement by teachers and trainers in industry would be likely to improve their ability to engender such skills.

An issue that was under-discussed by participants was the presence of large proportions of student-workers in many service industries. As discussed in the 'background' section, retail and fast food in particular rely heavily on students to staff their outlets, and yet, although other research has shown that such companies are well aware of the importance of students in their human resource and training regimes (Smith and Patton, 2007), it is interesting that the participants in the study reported in this paper did not raise this issue, despite their mentioning the need for trainers to take account of individual differences among learners and contexts. This omission may reflect an unconscious assumption that all teachers and trainers would be aware of the predominance of students in the workforce of many service industry companies; if so, this could be a dangerous assumption that needs to be corrected in the relevant qualifications and other development activities for teachers and trainers for the service industries.

\section{Acknowledgements}

The authors would like to thank the other members of the research team, Lauri Grace and Warren Payne; and the project's research assistant, Alicia Godycki. 


\section{References}

Baum, T. (2002), "Skills and training for the hospitality sector: a review of issues", Journal of Vocational Education and Training, Vol. 54 No. 3, pp. 343-64.

Booth, S. and Hamer, K. (2007), “Labour turnover in the retail industry”, International Journal of Retail \& Distribution Management, Vol. 35 No. 4, pp. 289-307.

Dougherty, K.J. (2003), "The uneven distribution of employee training by community colleges: description and explanation", The ANNALS of the American Academy of Political and Social Science, Vol. 586, pp. 62-91.

Greenbank, P., S. Hepworth, and J. Mercer. (2009). Term-time employment and the student experience, Education + Training, Vol. 51 No.1, pp. 43-55.

Hart, C., Stachow, G.B., Farrell, A.M. and Reed, G. (2007), "Employer perceptions of skills gaps in retail: issues and implications for UK retailers", International Journal of Retail \& Distribution Management, Vol. 35 No. 4, pp. 271-288.

Huddleston, P. and Hirst, C. (2004), “Are you being served? Skills gaps and training needs within the retail sector", Research Paper 53, Centre on Skills, Knowledge and Organisational Performance, Oxford and Warwick Universities, Oxford.

Jameson, S.M. (2000), “Recruitment and training in small firms”, Journal of European Industrial Training, Vol. 24 No. 1, pp. 43-49.

Maxwell, G., Watson, S. and Quail, S. (2004), "Quality service in the international hotel sector: a catalyst for strategic human resource development?”, Journal of European Industrial Training, Vol. 28 No. 2-4, pp. 159-82.

People1st. (2009), State of the nation report, executive summary. People1st, London.

Poulston, J. (2008), “Hospitality workplace problems and poor training: a close relationship”, International Journal of Contemporary Hospitality Management, Vol. 20 No. 4, pp. 412-427.

Pratten, J.D. (2003), “The training and retention of chefs", International Journal of Contemporary Hospitality Management, Vol. 15 No. 4, pp. 237-42.

Service Skills Australia. (2009a), Floristry, retail and wholesale services: Environmental scan, Service Skills Australia, Sydney.

Service Skills Australia. (2009b), Tourism, hospitality and events: Environmental scan, Service Skills Australia, Sydney.

Simons, M. and Smith, E. (2008), "The understandings about learners and learning that are imparted in Certificate IV level courses for VET teachers and trainers”, International Journal of Training Research, Vol. 6 No. 1, pp. 23-43.

Smith, E. and Patton, W. (2007). A serendipitous synchronisation of interests: employers and student-working. Evolution, revolution or status quo? The new context for VET. $10^{\text {th }}$ Conference of the Australian VET Research Association, Victoria University, Footscray Park, Vic, 11-13 April.

Smith, E. \& Smith, A. (2009). "Making training core business: Enterprise Registered Training Organisations in Australia”, Journal of Vocational Education and Training, Vol 61 No. 3, pp. 287-306.

Smith, E. and Keating, J. (2003), From training reform to Training Packages, Social Science Press, Tuggerah Lakes NSW. 
Smith, E. and Wilson, L. (2002), "The new child labour? The part-time school student workforce in Australia”, Australian Bulletin of Labour, Vol. 28 No. 2, pp. 118-134.

Smith, E., Brennan Kemmis, R., Grace, L. \& Payne, W. (2009), Workforce development for service industries VET practitioners, Service Skills Australia, Sydney. Available at http://www.serviceskills.com.au/dmdocuments/projects/new\%20deal/wfd_full_report.pdf

Smith, E., Comyn, P., Brennan Kemmis, R. and Smith, A. (2009), High quality traineeships: Identifying what works, National Centre for Vocational Education Research, Adelaide.

Wickham, J., Moriarty, E., Bobek, A. and Salamonska, J. (2009), "Working in the gold rush: Polish migrants' careers and the Irish hospitality sector”, in Bolton, S. and Houlihan M. (Eds.), Work Matters: Critical reflections on contemporary work, Palgrave Macmillan, Basingstoke, UK. 


\section{TABLES}

Table 1. Focus group participants - retail including floristry

\begin{tabular}{|l|l|l|l|}
\hline $\mathbf{1 .}$ & $\begin{array}{l}\text { Retail } \\
\text { (hardware) }\end{array}$ & Vic & Hardware employers' association of Victoria \\
\hline $\mathbf{2 .}$ & Retail / Floristry & Vic & Consultant trainer \\
\hline $\mathbf{3 .}$ & Retail & Vic & Grocery employers' association Australia \\
\hline $\mathbf{4 .}$ & Retail & Vic & Skills Council, Victorian branch \\
\hline $\mathbf{5 .}$ & Retail & NSW & Major low-cost supermarket chain \\
\hline $\mathbf{6 .}$ & Floristry & NSW & Small floristry enterprise \\
\hline
\end{tabular}

Table 2. Focus group and interview participants - hospitality including travel and tourism

\begin{tabular}{|c|c|c|c|}
\hline 1. & Hospitality & NSW & $\begin{array}{l}\text { Group Training Organisation (which employs apprentices } \\
\text { and trainees and leases them to employers) }\end{array}$ \\
\hline 2. & Travel & NSW & Travel agent chain \\
\hline 3. & Hospitality & NSW & Hotel group \\
\hline 4. & Hospitality & NSW & Ethnic restaurant \\
\hline 5. & \begin{tabular}{|l|} 
Tourism/Hospitality \\
\end{tabular} & Qld & Registered Training Organisation \\
\hline 6. & Hospitality & Qld & Consultant trainer \\
\hline 7. & Hospitality & Qld & Hotel group \\
\hline 8. & Hospitality & Qld & Skills Council, Qld branch \\
\hline \multicolumn{4}{|c|}{ Interviews } \\
\hline 1 & Hospitality & NSW & Casino \\
\hline 2 & Hospitality & National & Hospitality employers' association \\
\hline
\end{tabular}

Table 3. Retail industry representatives' $(n=5)$ views of the ideal balance for VET practitioners delivering training for their industry, between skills and knowledge about the industry or about education.

\begin{tabular}{|c|c|c|c|c|c|}
\hline & Industry & & $\mathrm{Kn}$ & & Education \\
\hline Respondent Category & 1 & 2 & 3 & 4 & 5 \\
\hline A (Employer) & & 1 & & 1 & \\
\hline B (GTO) & & & 1 & & \\
\hline C (Employer association) & & 2 & & & \\
\hline \multicolumn{6}{|l|}{$\mathrm{D}$ (other) } \\
\hline Total & 0 & 3 & 1 & 1 & 0 \\
\hline
\end{tabular}


Table 4. Hospitality industry representatives' $(n=10)$ views of the ideal balance for VET practitioners delivering training for their industry, between skills and knowledge about the industry or about education.

\begin{tabular}{|l|c|c|c|c|c|}
\hline & Industry & & & \\
\\
\hline Respondent Category & & $\mathbf{2}$ & $\mathbf{3}$ & $\mathbf{4}$ & $\mathbf{5}$ \\
\hline A (Employer) & $\mathbf{1}$ & 2 & & 1 & \\
\hline B (GTO) & 3 & & & & \\
\hline C (Employer association) & 1 & & & 1 & \\
\hline D (other) & & & & 2 & \\
\hline Total & & 2 & & & 0 \\
\hline
\end{tabular}

